Dossiê "Arquitetura escolar: diálogos entre o global, nacional e regional na história da educação":

Apresentação

\title{
ARQUITETURA ESCOLAR: DIÁLOGOS ENTRE O GLOBAL, O NACIONAL E O REGIONAL NA HISTÓRIA DA EDUCAÇÃO
}

\author{
Tatiane de Freitas Ermel ${ }^{1}$ \\ Marcus Levy Bencostta²
}

O ano de 2018 marcou duas décadas da publicação no Brasil da obra organizada por Antonio Viñao Frago e Agustín Benito Escolano, intitulada "Currículo, Espaço e Subjetividade: arquitetura escolar como programa" (1998)3. Considerada na época a "caixa preta" dos estudos na área de história da educação,

1 Universidade Regional Integrada do Alto Uruguai e das Missões (URI), Frederico Westphalen/RS, Brasil.

2 Universidade Federal do Paraná (UFPR), Curitiba/PR, Brasil.

3 Cabe assinalar que a obra publicada no Brasil esteve vinculada ao dossiê sobre espaços escolares, organizado na Revista Historia de la Educación/Salamanca (1994), com 23 artigos e bibliografia específica sobre o tema. 
o espaço e a arquitetura escolar tem sido explorados em diversas pesquisas estudos no país, exercitando uma importante interlocução entre história, educação e arquitetura4.

Revisitando a importância desta publicação, que teve sua segunda edição em 2001, este dossiê propõe dialogar sobre a arquitetura escolar em perspectiva global, nacional e regional, enfatizando o momento de configuração e de consolidação das redes de ensino primária em diferentes países e a constituição da escola como uma instituição independente das demais, o que lhe configurou uma identidade própria. Nesta conjuntura, consideramos a concepção funcional e simbólica que a arquitetura escolar incorporou, tanto nos meios urbanos como nos rurais, acompanhando as demandas pedagógicas, as questões higiênicas, assim como os discursos em torno da formação do cidadão através da escola.

A historiografia da arquitetura escolar brasileira nos últimos anos expressa nos diferenciados temas e tópicos abordados, a sua importância para o campo da História da Educação. É evidente que algumas lacunas necessitam ser melhor investigadas, tanto do ponto de vista dos recortes temporais como de novas prospecções temáticas. E, no intuito de visibilizar a trama discursiva e as ações que permeiam essas diferentes dimensões, consideramos, por um lado, a circulação das ideias pedagógicas no âmbito internacional e, por outro, as particularidades nacionais e regionais. Para tanto, objetivamos nesta proposta refletir sobre a arquitetura destinada para a escola primária em diferentes espaços geográficos, entre as últimas décadas do século XIX e primeiras décadas do XX, valendo-se de diferentes pressupostos teóricos-metodológicos.

Nesta perspectiva, consideramos relevante a discussão acerca da transposição de modelos internacionais, os discursos contrastantes, os projetos, as materialidades, as incorporações simbólicas, assim como as representações e a construção visual dos edifícios escolares no traçado urbano e, também, de sua

\footnotetext{
4 Para citar algumas das primeiras produções brasileiras, específicas do campo da História da Educação: Faria Filho (1996); Souza (1997), Moussatche; Mazzoti; Mazzoti (2000), Baltar (2001), Buffa; Pinto (2002), Buffa; Nosella (2002), Dórea (2003) e Bencostta (2005).
} 
configuração enquanto elemento considerado essencial para a melhoria e/ou qualidade das atividades de ensino e aprendizagem. Ainda, consideramos importante analisar a atuação dos intelectuais e diferentes profissionais, sobretudo médicos, pedagogos, engenheiros e arquitetos na elaboração de discursos e modelos em torno do espaço escolar idealizado, projetado e construído para infância moderna.

Os artigos que integram esse dossiê trazem experiências de seis países, sendo eles: Itália, Luxemburgo e Suíça, da Europa; Argentina, Brasil e México, da América Latina. O estudo de Marianne Helfenberger e Catherina Schreiber apresenta a discussão em torno da construção do cidadão através dos edifícios escolares em uma conjuntura multilíngue, analisando os casos de Luxemburgo e Suíça. As autoras problematizam a importância destes espaços no âmbito nacional e local, convertendo-se em agentes de planificação social e tensionando aspectos da arquitetura escolar no processo de unificação e diferenciação dos indivíduos.

Analisando o caso da Itália, Valéria Viola retrata os discursos nacionalistas direcionados para a construção dos espaços escolares pelo regime fascista, delineando sua fisionomia através do estudo de diferentes fontes arquivísticas e impressas. A autora identifica um lento processo de instalações e de desenvolvimento dos edifícios escolares, entre os anos 1909 e 1939, destacando a figura ministerial de Giuseppe Bottai e a importância do Regulamento de 1939, que desvincula a ideia de edifício escolar de qualquer tipo de adaptação. Além disso, o mesmo Regulamento expressa as indicações para construções de escolas rurais, compreendidas como elemento fundamental de construção da civilização fascista.

Em sua pesquisa sobre o México, Carlos Ibarra analisa as mudanças empreendidas pela Reforma Constitucionalista na Cidade do México, entre os anos de 1914 e 1917, valendo-se do movimento de desenvolvimento da educação e a expansão da rede de ensino para as camadas populares. $\mathrm{O}$ autor evidencia $\mathrm{o}$ movimento de construção dos edifícios escolares de acordo com as necessidades 
funcionais e higiênicas, problematizando a descentralização educativa do Estado e a perspectiva local, através do empoderamento dos municípios e a coação dos proprietários agrícolas, industriais e de mineração para o estabelecimento escolas em suas respectivas jurisdições.

O estudo desenvolvido por Nicolás Arata nos remonta ao momento da inauguração de um conjunto de 54 edifícios escolares, na cidade de Buenos Aires/Argentina, entre os anos de 1884 e 1886. O autor analisa o movimento de expansão e redefinição dos espaços escolares inserido em um processo de reformas sociais em um sentido mais amplo, e, entre palavras e ações, as insígnias deste evento inaugural, destacando os discursos, os rituais e a repercussão deste empreendimento na imprensa.

A pesquisa dos organizadores deste dossiê remete ao caso do Brasil, mais especificamente, sobre a arquitetura escolar de duas capitais do sul do país, as cidades de Curitiba/PR e de Porto Alegre/RS, analisando o processo de implementação da escola graduada e suas relações com o traçado urbano. Valendo-se de um exercício reflexivo comparativo, os autores consideraram o estabelecimento de relações entre o interior e o exterior, reconstruindo o significado da arquitetura escolar, nessas duas cidades, e sua representação para o cenário da construção de escolas no Brasil, nos primeiros decênios do século XX.

As investigações sobre arquitetura escolar acima apresentadas desvelam conjunturas históricas que propulsionaram discursos e ações em torno dos espaços escolares. Dentre seus elementos funcionais e simbólicos, estão matizadas propostas educativas, programas governamentais, reformas políticas, concepções pedagógicas, demandas de diferentes grupos sociais e os diversos sujeitos que conceberam e que transformaram essas edificações em lugares memoráveis. 


\section{REFERÊNCIAS}

BALTAR, Francisca Maria Teresa dos Reis. Arquitetura de escolas no século XIX. Primeiras escolas construídas no Brasil. História da Educação, Asphe, v. 5 , n. 10, p. 53-84, set. 2001.

BENCOSTTA, Marcus Levy (org.). História da educação, arquitetura e espaço escolar. São Paulo: Cortez, 2005.

BUFFA, Ester; NOSELLA, Paolo. Schola mater. A antiga Escola Normal de São Carlos, 1911-1933. São Carlos: Editora da Universidade Federal de São Carlos/Fapesp, 2002.

BUFFA, Ester; PINTO, Gelson de Almeida. Arquitetura e educação: organização do espaço e propostas pedagógicas dos grupos escolares paulistas, 1893-1971. São Carlos: Brasília: EdUFSCar, Inep, 2002.

DÓREA, Célia Rosângela Dantas. Anísio Teixeira e a arquitetura escolar: planejamento escolas, construindo sonhos. 2003. 255 f. Tese (Doutorado em Educação) - Programa de Pós-Graduação em Educação, História, Política, Sociedade, Pontifícia Universidade Católica de São Paulo, São Paulo, 2003.

ESCOLANO BENITO, Agustín. La arquitetura como programa: espacio-escuela y curriculum. Revista Historia de la Educación, n. 12-13, p. 97-120, 199394.

FARIA FILHO, Luciano Mendes de. Dos pardieiros aos palácios: forma e cultura escolares em Belo Horizonte - 1906/1918. 1996. 362 f. Tese (Doutorado em Educação) - Programa de Pós-Graduação em Educação, Universidade de São Paulo, São Paulo, 1996.

MOUSSATCHE, Helena; MAZZOTI, Alda Judith Alves; MAZZOTI, Tarso Bonilha. Arquitetura escolar: imagens e representações. Revista Brasileira de Estudos Pedagógicos, Brasília, v. 81, n. 198, p. 229-315, mai./ago. 2000.

SOUZA, Rosa Fátima de. Templos de civilização: um estudo sobre a implantação dos Grupos Escolares no estado de São Paulo (1890-1910). 1997. 285 f. Tese (Doutorado em Educação) - Programa de Pós-Graduação em Educação, Universidade de São Paulo, São Paulo, 1997.

VIÑAO FRAGO, Antonio. Del espacio escolar y la escuela como lugar: propuestas y cuestiones. Revista Historia de la Educación, n. 12-13, p. 1774, 1993-94. 
VIÑAO FRAGO, Antonio. El espacio escolar: introducción. Revista Historia de la Educación, n. 12-13, p. 11-16, 1993-94.

VIÑAO FRAGO, Antonio; ESCOLANO BENITO, Agustín. Currículo, espaço subjetividade: a arquitetura como programa. Trad. Alfredo Veiga Neto. Rio de Janeiro: DP\&A, 1998.

TATIANE DE FREITAS ERMEL é professora do Programa de Pós-Graduação em Educação da Universidade Regional Integrada do Alto Uruguai e das Missões (URI), em Frederico Westphalen/RS. Doutora em Educação pelo Programa de Pós-Graduação em Educação da Pontifícia Universidade Católica do RS (PUCRS) (2013-2017), mestre em Educação pela mesma instituição (2009-2011), bacharel e licenciada em História pela Faculdade de História/PUCRS (2008). Realizou estágio na Universidad Nacional de La Plata (UNLP), Argentina (2009) e Doutorado Sanduíche na Universidad Complutense de Madrid (UCM), Espanha (2014-2015). Desenvolve pesquisas na área da História da Educação, principalmente os temas: cultura, patrimônio e memória escolar; espaço e arquitetura escolar; imprensa pedagógica, entre o final do século XIX e início do XX.

E-mail: tati.ermel@yahoo.com.br

(C) http://orcid.org/0000-0003-2002-5101

MARCUS LEVY BENCOSTTA é professor Titular de História da Educação da Universidade Federal do Paraná (UFPR), em Curitiba/PR, com pósdoutorado pela École Nationale Supérieure d'Architecture de Versailles (Énsav), França (2007-2008) e aperfeiçoamento em Arquitetura Escolar pela Université du Québec à Montréal (Uqam), Canadá (2004). É bacharel e licenciado em História pela Universidade Estadual de Campinas (Unicamp) (1991), mestre em História Social pela Universidade de São Paulo (USP) (1993) e doutor em História Social pela USP (1999). Pesquisador do CNPq, editor-chefe da Educar em Revista (2002-2003 / 2013-2014) e editor-adjunto (2015-2016), Editor de Seção da Revista Brasileira de Educação (2016-atual).

E-mail: marcus@ufpr.br

(1) http://orcid.org/0000-0003-3387-7901

Recebido em: 10 de dezembro de 2018

Aprovado em: 14 de dezembro de 2018 